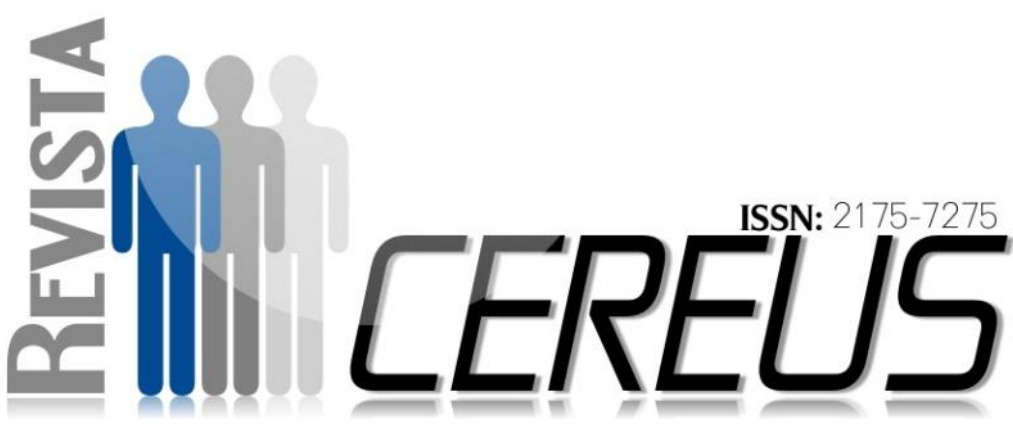

DOI: 10.18605/2175-7275/cereus.v9nep113-124.

\title{
- (DES)ACESSO À JUSTIÇA: O PROCESSO JUDICIAL ELETRÔNICO NO TOCANTINS
}

\section{BRITO, George Lauro Ribeiro de ${ }^{1}$ COSTA, Igor Rodrigues $\mathrm{da}^{2}$ MEDINA, Patrícia ${ }^{3}$ MELO, José Wilson Rodrigues de $\mathrm{e}^{4}$ MOTA, Bhonny Soares de Sá 5 ROCHA, Suyene Monteiro da ${ }^{6}$}

\section{RESUMO}

Este trabalho é o resultado de uma pesquisa bibliográfica que tem como foco principal a revisão de literatura acerca da informatização judicial do processo. O problema de pesquisa visou investigar se a ferramenta de tecnologia da informação utilizada pelo Poder Judiciário Estadual Tocantinense

\footnotetext{
${ }^{1}$ Doutor em Engenharia Elétrica pela Universidade de Brasília - UnB. Professor do programa de PósGraduação Stricto Sensu Mestrado Profissional e Interdisciplinar em Prestação Jurisdicional e Direitos Humanos pela Universidade Federal do Tocantins - UFT .

2 Mestrando profissional e interdisciplinar em prestação jurisdicional e direitos Humanos pela Universidade Federal do Tocantins - UFT em parceria com a Escola Superior da Magistratura tocantinense - ESMAT. E-mail correspondência: cigor3001@gmail.com.

3 Doutora em Educação pela Universidade Federal de Goiás - UFG. Professora do programa de PósGraduação Stricto Sensu Mestrado Profissional e Interdisciplinar em Prestação Jurisdicional e Direitos Humanos pela Universidade Federal do Tocantins - UFT.

4 Estágio Pós-Doutoral na Université de Montréal - UdM, Canadá. Doutor em Didacta e Organización Escolar pela Universidade de Santiago de Compostela - USC, Espanha. Professor do programa de PósGraduação Stricto Sensu Mestrado Profissional e Interdisciplinar em Prestação Jurisdicional e Direitos Humanos pela Universidade Federal do Tocantins - UFT.

5 Mestranda Profissional e Interdisciplinar em Prestação Jurisdicional e Direitos Humanos pela Universidade Federal do Tocantins - UFT .

6 Doutora em Biotecnologia pela Universidade Federal do Amazonas - UFAM. Professora do programa de Pós-Graduação Stricto Sensu Mestrado Profissional e Interdisciplinar em Prestação Jurisdicional e Direitos Humanos pela Universidade Federal do Tocantins - UFT.
} 
corrobora ou não com o acesso ao sistema de justiça pelo jurisdicionado. A pesquisa bibliográfica sobre o "processo judicial eletrônico" combinada com o conjunto da legislação vigente em março de 2017 sobre o tema resultou em achados tanto pontos positivos quanto negativos no que diz respeito à informatização do processo. E conclui que a informatização judicial no Brasil constitui instrumento de acesso à justiça, especialmente porque aperfeiçoa e torna mais célere e eficiente o sistema de justiça

Palavras chave: Acesso à justiça. Informatização do processo. Processo judicial eletrônico e-PROC/TJTO.

\section{THE (DISACESS)ACCESS TO THE JUSTICE: THE ELECTRONIC JUDICIAL PROCESS IN TOCANTINS.}

\section{ABSTRACT}

This article is result of a bibliographic search that has as main focus the literature review about the judicial informatization of the process. The problem of this search looked to investigate if the new tool of information technology used by Tocantinense State Law Court helps or not with the access to Law Court system by people. The bibliographical search about the "electronic judicial process" with the Brazilian legislation in march of 2017 about the law subject-matter resulted in discovering as positives as negatives aspects about the judicial informatization of the process. And this article deduces that judicial information in Brazil is an instrument of access to justice, especially because it improves and makes more fast and efficient the justice system.

Keywords: Access to the justice. Informatization of the process. Electronic judicial process e-PROC/TJTO 


\section{INTRODUÇÃO}

Os autos, instrumento por meio do qual são depositadas as pretensões em juízo, foram se aperfeiçoando ao longo da história, seja no plano das normas seja no plano físico. Há quem se espante quando encontra algum processo antigo com folhas escritas à mão, pois antes do advento da máquina de escrever (o uso no Brasil se expandiu a partir da década de 1950 após a instalação da primeira fábrica) as petições eram feitas com caneta tinteiro.

A máquina de escrever, sem dúvida, trouxe maior agilidade para 0 processo. Mas foi no século $\mathrm{XX}$, com o surgimento do computador, e mais especialmente a partir da década de 1990, que o universo jurídico passou a ver a possibilidade de melhor aproveitamento da tecnologia a favor da diminuição do emaranhado de papéis que abarrotam, no Brasil e mundo afora, os cartórios judiciais, pois permitiu a escrita e registro eletrônico de dados.

O primeiro grande passo do Poder Judiciário Brasileiro com relação à transmissão de dados processuais por meio da tecnologia deu-se com a lei № 9.800 , de 26 de maio de 1999 , conhecida como a "Lei do Fax", que permitiu às partes à utilização de sistema de transmissão de dados para a prática de atos processuais, devendo os originais fossem entregues posteriormente em juízo, conforme disciplina a lei em tela.

A transmissão de dados por meio do fac-símile encurtou distâncias no judiciário nacional. Mandados de prisões, ações cautelares, mandados de segurança, habeas corpus, dentre outros, começaram a percorrer o país de norte a sul e de leste a oeste por meio da comunicação conhecida por "fax", que se caracterizava por um telecópia que é tecnologia de comunicação usada para transferência de modo remoto de documentos, via rede telefônica, o que se apresentou à época como uma grande vantagem às grandes distâncias se comparado o envio de documentos pelo correio.

Dois anos depois nasce a Lei no $10.259 / 2001$, a qual ao mesmo tempo que criou os juizados especiais federais tratou também da informatização dos mesmos, inaugurando no ordenamento jurídico brasileiro normas sobre informatização do processo, ainda que restrita aos juizados especiais. 
A tecnologia foi avançando de tal forma que não se pode mais pensar num judiciário avesso às tecnologias da comunicação e da informação. Aos poucos, o judiciário foi se familiarizando com a utilização maciça de computadores, até que os tribunais se renderam à Internet, disponibilizando portais, diários eletrônicos e consultas processuais, especialmente a partir da década de 2010.

Como legislações esparsas foram surgindo aqui e acolá, sempre dando suporte a um ramo tecnológico a serviço da justiça, como por exemplo, o nascimento da certificação digital, a criação da Infra-Estrutura de Chaves Públicas Brasileira - ICP Brasil, a penhora on line, a vídeo conferência etc., veio o legislador e disciplinou a informatização do processo por meio da Lei no 11.419/2006.

A celeridade processual e a duração razoável do processo constitui uma preocupação de natureza técnica, estratégica e conceitual voltada à efetividade da prestação jurisdicional que ocupa estudiosos e técnicos. É certo que as tecnologias da comunicação e informação digitais seja parceira desse novo paradigma processual que surge no século XXI, eis que nasce a era dos autos informatizados.

O Tribunal de Justiça do Estado do Tocantins, a partir das disposições da Lei no 11.419/2006, considerando a necessidade de regulamentar o processo eletrônico implantado pela Resolução ํo 01/2011 do TJTO, a necessidade de consolidar os procedimentos do processo judicial eletrônico na jurisdição estadual tocantinense, a necessidade de trabalhar de forma integrada nos dois graus de sua jurisdição e a necessidade de otimizar a gestão documental, edita a Instrução Normativa 5/2011, que implanta e regulamenta 0 processo judicial eletrônico - e-Proc/TJTO, no âmbito do Poder Judiciário do Estado do Tocantins.

\section{MATERIAIS E MÉTODOS}

Foi realizada uma pesquisa Escola Superior da Magistratura bibliográfica sobre "processo judicial Tocantinense - ESMAT, onde foram eletrônico" disponível no acervo da encontradas obras sobre o tema. 
Feita a consulta bibliográfica, passou-se à leitura da legislação vigente acerca do tema, mais especificamente na Lei oㅜ11.419/2006, que dispôs sobre a informatização do processo judicial, e na Instrução Normativa 5/2011, que implantou e regulamentou 0 processo judicial eletrônico (e-Proc/TJTO), no âmbito do Poder Judiciário do Estado do
Tocantins, além de outras legislações, conforme consta nas referências.

Em seguida, foi realizada leitura e fichamentos do material selecionado, para, posteriormente, analisá-los, a fim de elucidar possíveis problemas levantados. Por fim, foi realizada a interpretação, bem como apresentados os resultados da pesquisa.

\section{O SISTEMA PROCESSUAL ELETRÔNICO E-PROC/TJTO}

O e-Proc/TJTO surgiu com a Lei no 11.419/2006, que facultou aos órgãos do Poder Judiciário informatizar integralmente o processo judicial, para torná-lo acessível pela Internet, tendo como objetivo principal a celeridade e a busca pela produtividade na prestação jurisdicional.

A Lei no $11.419 / 2006$ propôs a validação das atividades no processo totalmente eletrônico. Dispondo sobre: a informatização do processo judicial; as formas de comunicação eletrônicas e atos processuais; processo eletrônico e suas particularidades.

A partir desta lei $o$ ato processual realizado por meio eletrônico recebe a presunção legal de validade se realizado exclusivamente por esse meio. As leis antecedentes trouxeram ocorrência apenas na informatização de fases e/ou atos do trâmite processual.

O Tribunal de Justiça do Tocantins (TJTO) ao implantar o sistema e-Proc/TJTO desenvolveu um suporte a consecução de todas as atividades processuais em meio eletrônico. $\mathrm{Na}$ Instrução Normativa $5 / 2011$ foram dispostos os procedimentos da informatização do processo judicial, especificando a respeito de acesso ao e-Proc/TJTO; usuários e respectivos credenciamentos; distribuição; peticionamento; consulta e sigilo; prática dos atos processuais; citação; intimação, notificação e requisição; 
substabelecimento; plantão judicial; audiência; perito e auxiliares do juízo; custas e despesas processuais; baixa e arquivamento; dos processos no Tribunal; feitos criminais.

O sistema e-Proc/TJTO foi implantando no Tribunal de Justiça no ano de 2012. Ao longo dos anos, várias adaptações foram realizadas, em decorrência de novas legislações, para

\section{4 ÓBICES DE ACESSO À JUSTIÇA}

A celeridade e eficiência na prestação jurisdicional são os elementos justificadores da implantação do e-Proc/TJTO. Por isso, será o objetivo deste artigo é realizar um paralelo entre a modernização da justiça e o princípio fundamental do acesso à justiça, que visa garantir a todos os envolvidos na relação processual amplo acesso e transparência no deslinde da causa.

$O$ acesso à justiça se encontra no art. 5o, XXXV da Constituição Federal de 1988, quando preconiza que "a lei não excluirá da apreciação do Poder Judiciário, lesão ou ameaça a direito". Portanto, devem-se respeitar os princípios constitucionais do contraditório, ampla defesa e o princípio da igualdade ou isonomia, otimização na prestação jurisdicional. Esse dinamismo levou a conquista, no ano de 2015, pelo Tribunal de Justiça do Estado do Tocantins, o selo $100 \%$ eletrônico. A partir desta conquista foram implantados novos projetos, como: Secrim, Trabalho Remoto, Cojun, escrivanias em rede, SISCOCE, Nacom etc

pois só assim as partes terão condições de igualdade apesar de suas diferenças, na postulação de seus conflitos.

A expressão 'acesso à justiça' é reconhecidamente de difícil definição, mas serve para determinar duas finalidades básicas do sistema jurídico - o sistema pelo qual as pessoas podem reivindicar seus direitos e/ou resolver seus litígios sob os auspícios do Estado. Primeiro, o sistema deve ser igualmente acessível a todos; segundo, ele deve produzir resultados que sejam individualmente e justos. (CAPPELLETTI; GARTH, 1998, p. 08).

O sistema eletrônico eProc/TJTO é uma realidade no Estado do Tocantins, é um caminho sem volta. Pode-se destacar como principais avanços a redução de gastos com papéis, impressões e correio, o que beneficia na preservação do meio ambiente, tempo de tramitação do 
processo, celeridade nas penhoras on line, abreviando-se as execuções judiciais.

Entretanto, há uma parcela da população que não tem acesso aos meios eletrônicos de comunicação, que estão sendo penalizados, por falta de domínio da técnica da informática, e os que não possuem os computadores conectados com a rede de Internet para poderem ter acesso à justiça. Além dos que querem postular sozinhos, ou seja, sem assistência de um advogado, que precisarão adquirir uma assinatura eletrônica, além de escâner para postularem em juízo.

Como garantir o acesso a todos? Como produzir resultados individuais e socialmente justos? No Brasil, especialmente a região norte , apresenta índice de desigualdades sociais preocupantes, conforme levantamento do IBGE de 2014, por isto a busca pelo poder judiciário, como anseio de reparação, tem levado a um aglomerado de ações junto ao Tribunal de Justiça do Estado do Tocantins. Com destaque para as diversas formas de divulgação das informações, como jornais, rádio, televisão, web, que em dados, conforme relatório de atividades de 2015, disponível no site www.tjto.jus.br, foi calculado uma média de 16,6 vezes por dias. Com objetivo de divulgar e informa a população tocantinense.

O sistema e-Proc/TJTO não pode promover a exclusão, mas o contrário deve ampliar 0 acesso à justiça. Para tanto, deve ficar atento a pessoa do cidadão, para que ele não seja apenas um mero expectador, sujeito ao auxílio das pessoas, seja advogado, estagiário ou serventuário da justiça

Os cientistas políticos, sociólogos e historiadores há décadas buscam por democratização através do acesso à justiça.

Em relação ao Processo Eletrônico, deve-se atentar quanto à exclusão digital da população de baixa renda, pois a situação de desigualdade no Brasil é um agravante a ser considerado, portanto é muito comum encontrar pessoas que não têm computador ou acesso à Internet. Cabe ao Poder Judiciário não obrigar ou constranger as pessoas com a exclusão do mundo eletrônico, mas disponibilizar computadores em suas unidades judiciais para suprir eventuais ausências dos meios tecnológicos.

As práticas eletrônicas de atos processuais no novo Código de Processo Civil Brasileiro: 
Art. 194. Os sistemas de automação processual respeitarão a publicidade dos atos, o acesso e a participação das partes e de seus procuradores, inclusive nas audiências e sessões de julgamento, observadas as garantias da disponibilidade, independência da plataforma computacional, acessibilidade e interoperabilidade dos sistemas, serviços, dados e informações que o Poder Judiciário administre no exercício de suas funções. [Grifo nosso]
A acessibilidade do art. 194 tem o escopo de assegurar a qualquer pessoa 0 acesso à informação, fornecendo os aparelhamentos indispensáveis para a realização dos atos processuais pelos interessados.

\section{O ACESSO À JUSTIÇA POR MEIO ELETRÔNICO}

Nos moldes do processo tradicional, composto por autos físicos, conjunto ordenado de papéis presos por "grampo trilho" e até mesmo entrelaçados por meio de um barbante com outros autos, uma parte demandante procura um escritório de advocacia, que após o relato da suposta lide, assina uma procuração dando poderes para que o advogado a represente em juízo. Produzida a peça inicial, impressa e acompanhada das cópias necessárias, a mesma é encaminhada ao protocolo do Fórum para distribuição. Após, a petição é encaminhada a uma vara, onde será autuada.

A partir daí começam atos que podem levar a diferentes caminhos, a depender da natureza processual.

$$
\text { Uma mesma situação }
$$
envolvendo um sistema processual por meio eletrônico, onde um demandante envia um e-mail para seu escritório de advocacia, que lhe é de confiança, relatando a suposta lide, com procuração assinada digitalmente, juntamente com documentos digitalizados em imagens. $\mathrm{O}$ advogado adapta o relato em forma de petição, assina e distribui eletronicamente em juízo via acesso ao sistema eletrônico vigente no determinado Tribunal competente. O processo já se iniciou em juízo.

Processo Judicial Eletrônico em alguns pontos manifesta-se apenas como uma maneira diferente de realizar alguns Atos Processuais, em outros, implica uma verdadeira revolução conceitual. As formas de Intimação e de contagem de prazos têm que ser adequadas à realidade Virtual, onde tempo e espaço têm uma concepção distinta. (CLEMENTINO, 2008, p. 89)

Nesse novo modelo de sistema processual em meio eletrônico não é espanto que a própria citação, por exemplo, ocorra no mesmo dia de 
distribuição da inicial, o que, via de regra, não é possível no modelo de autos físicos, ou seja, em papel.

O tempo toma concepção distinta do horário forense, que passa a ser de 24 horas no plano virtual, em consonância com 0 art. 213 da Lei $n^{0}$ 13.105, de 16 de março de 2015 Código de Processo Civil (CPC), que diz que "a prática eletrônica de ato processual pode ocorrer em qualquer horário até as 24 horas (vinte e quatro) horas do último dia de prazo". A intimação ocorre de modo simultâneo para ambas partes demandantes, não há que se esperar os autos voltarem do gabinete e/ou serem devolvidos após a carga, os autos estarão disponíveis a qualquer tempo para consulta e manifestação.

Para que o processo atinja a efetividade é preciso que sejam superados alguns paradigmas na era da tecnologia da informação. A modernidade vai vencer o arcaísmo. Todos os sujeitos envolvidos devem contribuir para a implantação desse novo modelo de paradigma processual em meio eletrônico. $\mathrm{O}$ acesso à justiça deve se dar de forma ampla e a informatização do processo é primeiro passo para que se atinja uma jurisdição una, econômica e sem fronteiras.
A instituição da informatização do processo aparece como uma das medidas adequadas e eficazes para enfrentar o problema da celeridade e eficiência da prestação jurisdicional tanto almejada pela sociedade que busca uma solução rápida e justa em seus litígios e "um procedimento eletrônico é rápido e eficaz e as experiências vivenciadas no Brasil demonstram ser possível a inserção desta forma no processo." (ALMEIDA FILHO, 2008, P. 19).

Apesar de haver quem repudia as ferramentas tecnológicas no direito, não há como desconsiderar os benefícios advindos com os projetosmodelo em andamento na Justiça Brasileira.

O mais recente Código de Processo Civil Brasileiro cuidou por disciplinar a prática eletrônica de atos processuais em seus artigos 193 a 199. Dentre as regras no tangente ao acesso à justiça, destaca-se o art. 198.

Art. 198. As unidades do Poder
Judiciário deverão manter
gratuitamente, à disposição dos
interessados, equipamentos
necessários à prática de atos
processuais e à consulta e ao acesso
ao sistema e aos documentos dele
constantes.
Parágrafo único. Será admitida a
prática de atos por meio não
eletrônico no local onde não
estiverem disponibilizados os
equipamentos previstos no caput.

Art. 198. As unidades do Poder gratuitamente, à disposição dos interessados, equipamentos necessários à prática de atos processuais e à consulta e ao acesso ao sistema e aos documentos dele constantes.

Parágrafo único será admitida a eletrônico no local onde não estiverem disponibilizados equipamentos previstos no caput. 
Nota-se a preocupação do legislador em assegurar o acesso à justiça, inclusive aos mais necessitados, onde incube ao próprio Pode Judiciário a obrigação de oferecer gratuitamente os equipamentos necessários ao peticionamento e à consulta e acesso ao sistema (leia-se aqui: computadores com acesso à rede mundial de computadores - Internet), bem como na unidade judiciária em que esse serviço não seja possível que seja admitida a prática por meio não

\section{CONSIDERAÇÕES FINAIS}

A implantação do sistema processual eletrônico e-Proc/TJTO no Poder Judiciário do Estado do Tocantins corroborou com 0 aperfeiçoamento da Justiça.

Apesar do acesso à rede mundial de computadores - Internet não estar em todos os lares brasileiros, o acesso à justiça pode dar-se com a ajuda do próprio Poder Judiciário, criando mecanismos que possibilitem o exercício do direito de ação independentemente de ter um computador à mão.

É obrigação não só do Poder Judiciário, mas de todos os sujeitos do sistema de justiça, como o Ministério eletrônico, como o peticionamento em papel.

Resta, continuamente, o aprimoramento da informatização do processo para que possamos alcançar a efetividade da justiça. $\mathrm{Na}$ Justiça Estadual Tocantinense, o sistema processual eletrônico e-Proc/TJTO é um projeto que vem dando certo e que une todo o Poder Judiciário numa só jurisdição, com acesso simples pela rede mundial de computadores.

Público, Defensoria Pública e Advocacia promoverem condições de acesso aos usuários hipossuficientes, como a disponibilização de computadores com acesso à Internet aos jurisdicionados.

A ideia de informatização do processo implica em ideia de ampliação do acesso à justiça. Nessa nova ferramenta de autos em meio eletrônico é notório muito mais benefício e pouco prejuízo para o jurisdicionado. O processo em meio eletrônico encontrase amparado pelos princípios da igualdade, devido processo legal, contraditório e ampla defesa, publicidade, acesso à justiça, 
celeridade, oralidade, imediação, porque ela coloca o Judiciário ao instrumentalidade, economia e boa-fé, alcance do cidadão, a partir de um além de outros não menos importantes. computador com acesso à Internet.

A informação judicial no Brasil é um instrumento de acesso à justiça,

\section{AGRADECIMENTOS}

Os autores agradecem a Escola Superior da Magistratura Tocantinense Universidade Federal do Tocantins - ESMAT pela parceria com a UFT e o apoio a esse trabalho.

\section{REFERÊNCIAS}

ALMEIDA FILHO, José Carlos de Araújo. Processo eletrônico e teoria geral do processo eletrônico: a informatização judicial no Brasil. 2 ed. Rio de Janeiro: Forense, 2008. 466 p.;

Constituição da República Federativa do Brasil de 1988. Disponível em: <http://www.planalto.gov.br/ccivil 03/Constituicao/Constituicao.htm>. Acesso em: 23 abr. 2017.;

Lei no 9.800, de 26 de maio de 1999. Permite às partes a utilização de sistema de transmissão de dados para a prática de atos processuais. Disponível em: <http://www.planalto.gov.br/ccivil 03/leis/L9800.htm>. Acesso em: 23 abr. 2017.;

Lei no 11.419, de 19 de dezembro de 2006. Dispõe sobre a informatização do processo judicial; altera a Lei no 5.869, de 11 de janeiro de 1973 - Código de Processo Civil; e dá outras providências. Disponível em:

<http://www.planalto.gov.br/ccivil 03/ ato2004-2006/2006/lei/L11419.htm>. Acesso em: 23 abr. 2017.;

Lei no 13.105, de 16 de março de 2015. Código de Processo Civil. Disponível em: <http://www.planalto.gov.br/ccivil 03/ ato2015-2018/2015/lei/L13105.htm>. Acesso em: 23 abr. 2017.;

CAPPELLETTI, Mauro; GARTH, Bryant. Acesso à justiça. Tradução de Ellen Gracie Northfleet. Porto Alegre: Ed. Sérgio Antonio Fabris, 1998.;

CLEMENTINO, Edilberto Barbosa. Processo judicial eletrônico: o uso da via eletrônica na comunicação de atos e tramitação de documentos processuais sob o enfoque histórico e principiológico, em conformidade com a Lei 11.419, de 19.12.2006. Curitiba: Juruá, 2008. 209 p.; 
PARIZI, Kelly Aparecida. O PJE E O JUS POSTULANDI NA JUSTIÇA DO TRABALHO: O PROBLEMA DO ACESSO À JUSTICA. Anais do V Simpósio Internacional de Análise Crítica do Direito (V SIACRID), 2015. p. 5.;

PEREIRA, Sinara Cristina da Silva. Processo judicial eletrônico: estudo da implantação no Tribunal de Justiça do Estado do Tocantins. 2016.117f. Dissertação (Mestrado Profissional em Prestação Jurisdicional e Direitos Humanos) - Universidade Federal do Tocantins - UFT, Palmas, 2016.;

TOCANTINS. Poder Judiciário. Instrução normativa no 5, de 24 de outubro de 2011.

Regulamenta o processo judicial eletrônico - e-Proc/TJTO, no âmbito do Poder Judiciário do Estado do Tocantins e dá outras providências. Disponível em:

<http://wwa.tjto.jus.br/elegis/Home/lmprimir/423>. Acesso em: 23 abr. 2017. 